\title{
THE USE OF BPMN FOR MODELLING THE MES LEVEL IN INFORMATION AND CONTROL SYSTEMS
}

\author{
DOI: 10.12776/QIP.V17I1.68
}

\author{
PETER MICHALIK, JÁN ŠTOFA, IVETA ZOLOTOVÁ
}

\section{BACKGROUND}

Process modelling is increasingly used in the design of information systems. Customers and their key requirements for business solutions, supporting BPM (Business Process Management) have a large proportion of this fact. One of the outputs of process modelling tends to be a process map, which is either part of several processes, or even completely all processes within an organization. Process models are used primarily to support the management, re-engineering processes and documentation of business processes. Today, however, there are increasing efforts to exploit the potential of process maps in a wider sense (Zolotová, et al., 2012a). We have in mind, particularly, the increasing number of attempts to use this methodology in the design of various information systems. The process model has a large potential to be used in the design of information and control systems (ICS), for example, an MES - Manufacturing Execution System. It can be used as a device for an analysis of the current state of an existing information and control system. On the other hand, it can also be used for the supporting processes of an information and control system. There are a lot of standards for creating process models, or even business models, process maps (Zolotová et al., 2011). The most important are EPC (Event-driven Process Chain) diagrams, BPMN (Business Process Model and Notation) and UML (Unified Modelling Language).

The issue of modelling information and control systems is currently of interest to several authors. While Bordbar et al. (2000) prefers the use of Petri nets and UML, Zor et al. (2010) shows the significance of a BPMN standard for modelling of manufacturing processes. Furthermore, we can mention an experiment with workflow modelling in productions systems, using Activity Diagrams made by Bastos et al. (2002). Another interesting publication by García-Domínguez at al. (2012) compares BPMN 2.0 with other notations for manufacturing processes. 


\section{THE ROLE OF A MES WITHIN INFORMATION AND CONTROL SYSTEMS}

Automation is an important part in production. This is related to an increase in productivity and efficiency in innovation. High complexity of managing industrial production is determined by a mutual interaction of these variables. The manufacturing process is usually a result of an interaction of several subsystems, creating a hierarchy (ICS). Each layer corresponds to an individual level of control. In this paper, ICS are assumed to have three levels:

- Lowest level (technological level),

- Intermediate level (MES, SCADA - Supervisory control and data acquisition),

- Top level (enterprise management level).

The technological level is often referred as a process level. It is an interface of production and includes product lines, various machines and equipment, which are often integrated to sensors and actuators, communicating through technology networks with control computers - PLC (Programmable Logic Controller) (Jadlovský et al., 2010).

The intermediate level extends a general view and technological details are a minor factor. At this level, compliance plan (production, transport, distribution) becomes the most important factor. Required information to manage at this level can be resource availability, planning closures, holidays, volumes of production and so on. An information system that manages and supports decision-making at this level is the tool of category MES. Manufacturing Execution Systems are information technology systems that manage manufacturing operations in factories. On the other hand, SCADA, represents a type of industrial control systems, that monitor and control industrial processes existing in the physical world. (Zolotová, et al., 2012b).

Enterprise management level is a top layer. A key criterion for senior management is making a profit. The basis for evaluation of the cost-effectiveness are various reports that are generated by the accounting information system module at this level. These systems tends to speak ERP (Enterprise Resource Planning). These systems integrate internal and external management information across an organization (Michalik, 2012).

\section{MES SYSTEMS AND REQUIREMENTS FOR THEIR MODELLING}

Currently, the number of attempts to model MES systems is increasing. There are a lot of existing modelling techniques and standards, such as process maps, UML 
or functional blocks. There are technical and process criteria for the modelling standards:

- Temporal descriptions,

- Synchronization processes,

- Description of the behaviour of processes,

- Structure processes,

- Representation,

- Graphical representation of rules and queries,

- Support for multiple points of view.

The issue of the actual design of MES is broad functionality, which can be divided to different managements, such as

- Operational management of production,

- Operational quality management,

- Maintenance management.

Consequently, the design and modelling MES level is an interdisciplinary process. Many experts (process-management, production operators, and IT specialists) are now trying to integrate their visions about modelling MES systems (Ricken \& Vogel-Heuser, 2010).

\section{APPLICATION}

At first, we analysed the production line, located in our laboratory at the Department of Cybernetics and Artificial Intelligence. This production line has been a subject of several thesis solutions. It means that our task was to construct a model based on our knowledge of the production line.

In the second step, identification of basic MES function was necessary. (MES systems offer 11 basic functions by MESA organization) (MESA, 2012). We modelled all these functions as separate sub processes, but this article describes only the function of management maintenance. It is important to note that modelling was carried out across all levels of ICS, because the MES is the integration between layers of ICS, and a lot of processes are actually interaction between these layers.

The next step was a selection of a modelling standard and a supporting software product. We chose the BPMN standard and QPR ProcessGuide software. For 
comparison, we modelled some functions of MES using the UML Activity Diagram. For this purpose, PowerDesigner application was selected.

To summarize, we used the BPMN standard for modelling, on the other hand, we used the UML Activity Diagram to indicate other options. At the end of this article, we compare these two technologies for designing the MES level of information and control systems. Nevertheless, the key issue of this article is a description of the use of the BPMN standard. It means, that demonstration of UML Activity Diagram is not included in this article, although identification of comparison criteria is a part of this article. It is very important to identify a number of comparison criteria and give them points. Based on these criteria, the sum of points can determine a better approach for modelling the MES level in ICS.

\subsection{The flexible production line}

The flexible production line (Figure 1) is divided into six positions, which are actually technology zones. A specific role in the whole production process is performed in each zone. The positions are following:

- Filling pallet with products - the zone ensures, that pallets are filled with products in the form of cubes,

- Camera control and transfer between conveyors - in this post, there is camera control while folded pallets are moved to another conveyor belt,

- Folding and move of a pallet from a shelf - if the test of quality is successful, a pallet is moved to a shelf,

- Transfer between conveyor number 2 and conveyor number 1 ,

- Empty pallets - if a palette is not folded successfully, products are poured into vibrating tray,

- Classification of goods (cubes) by colour - this technology area is separate part and does not interfere directly with the production process (Hošák, 2012). 


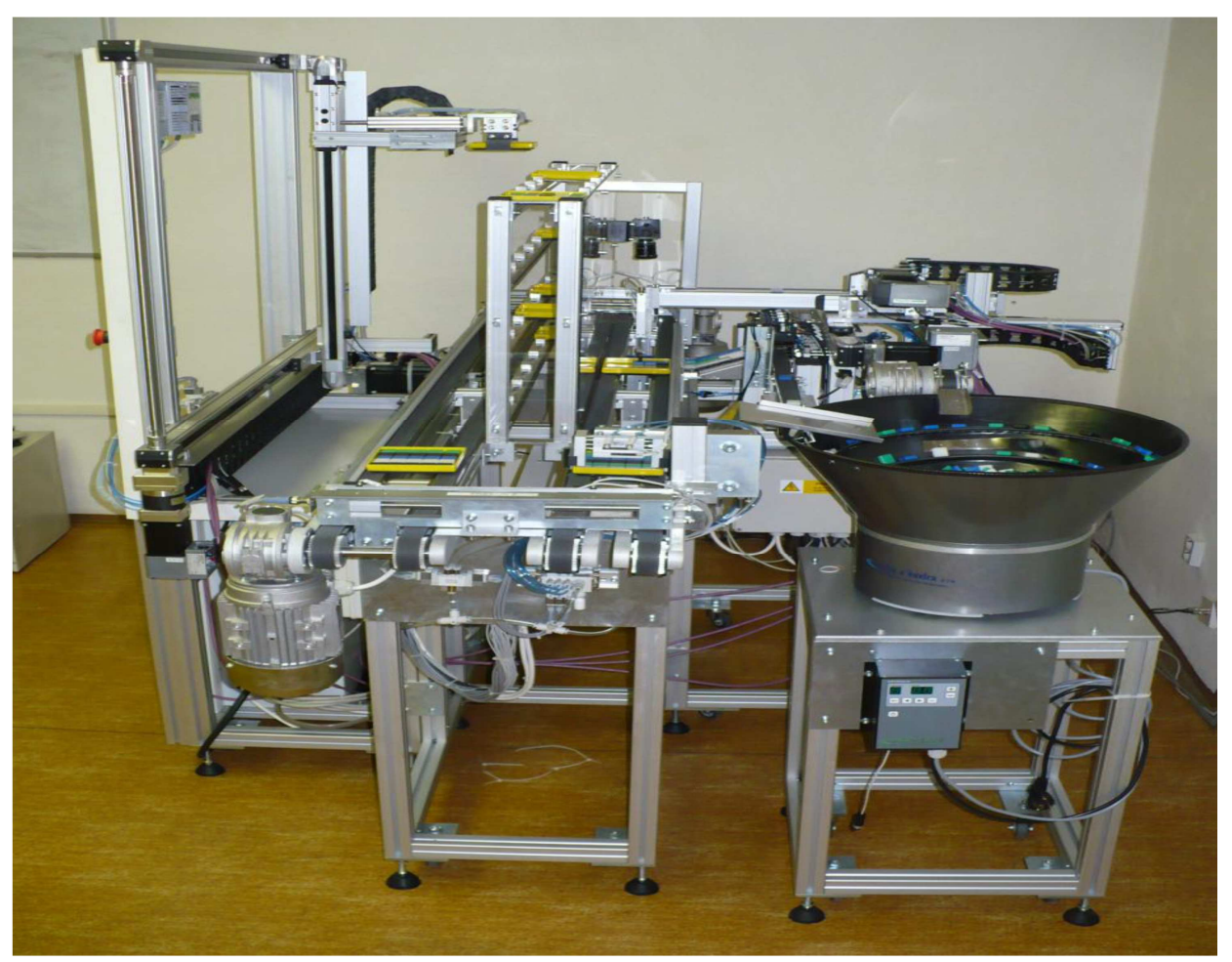

Figure 1 - The flexible production line (Hošák, 2012)

For illustration, there is an architecture ICS in Figure 2 (Department of Cybernetics and Artificial Intelligence).

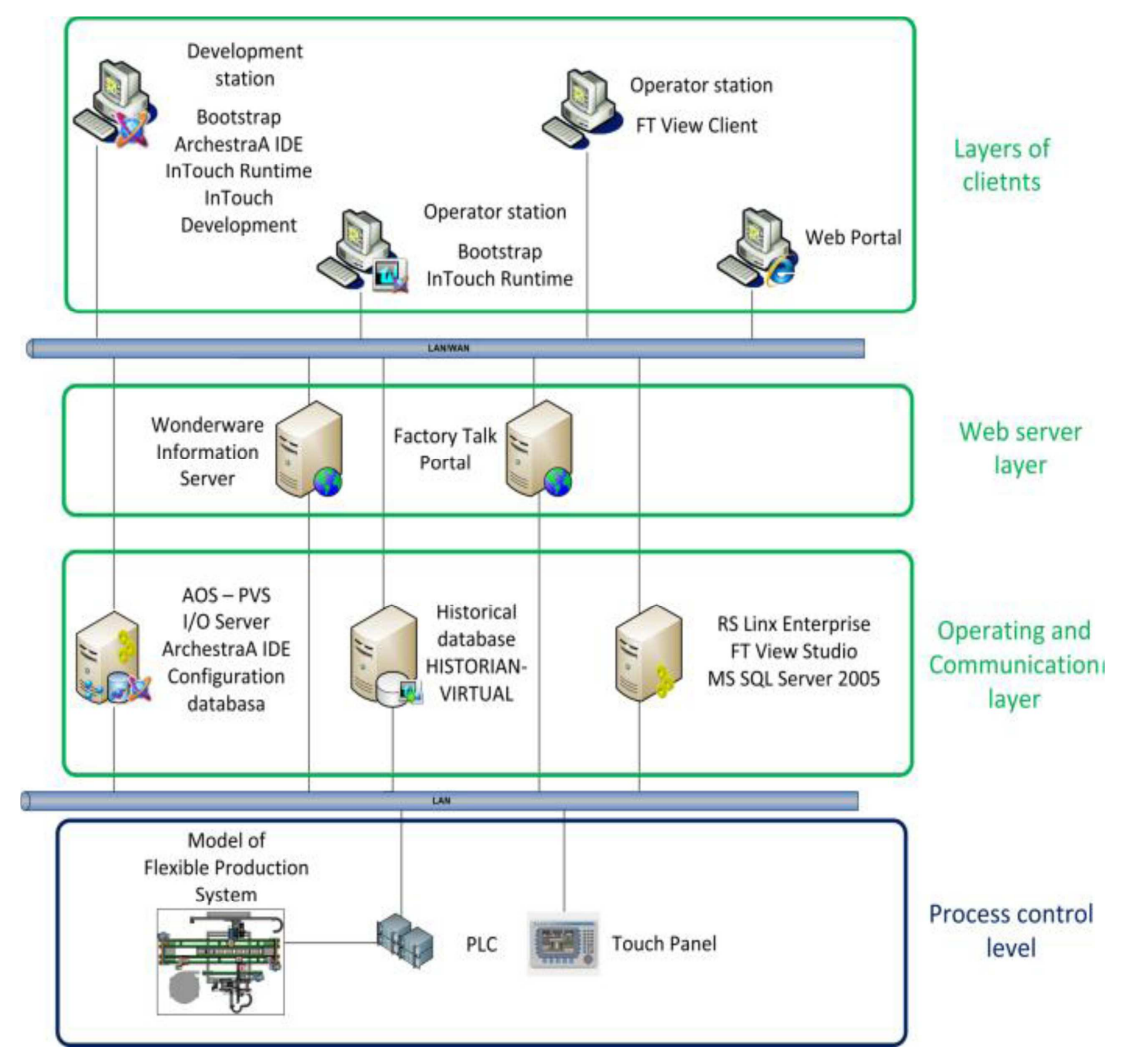

Figure 2 - Architecture of ICS (Laciňák et al., 2012) 


\subsection{BPMN model for the function of management maintenance}

In Figure 3, we can see a BPMN for the function of management maintenance, which is described in following lines.

The process itself begins with the technological level of the production process that is intentionally represented as a single task (for clarity). The production process is continuously collecting process data that are sent to the MES database.

Process data that can be in different forms (tables, reports, etc.) is analysed and compared with appropriate values in the next step. There are modelled decision flows through the exclusive gates. If the values in order are correct, a record about control will be created and sent back to the MES database. For this part, we used a graphical element event type - message.

The next tasks (identification of faulty devices, identifying the faults) are modelled through an exclusive gateway again and can produce two different results - know or unknown fault. In the case of a known fault, the system will require a maintenance plan from the available database. This query can be executed by a generated SQL script. A maintenance plan is sent to maintainers in its final phase, and this step is modelled through the end event type - message.

Otherwise, when the fault is unknown, standard maintenance must start in order to determine where the fault is located. MES provides a standard maintenance plan in the form of a Gantt chart (we used an artefact element). The maintenance is carried out in stages (tasks in BPMN) - servicing, fault finding, analysis and then creating an error $\log$.

If the fault is analysed and documentation of fault is created, the documentation is sent to the MES databases and chances of faster troubleshooting in the future is increased. At the same time, through the end event - message, the signal about the end of the maintenance is sent to the MES level. These two activities run running at the same time and, therefore, we used a parallel gateway in modelling.

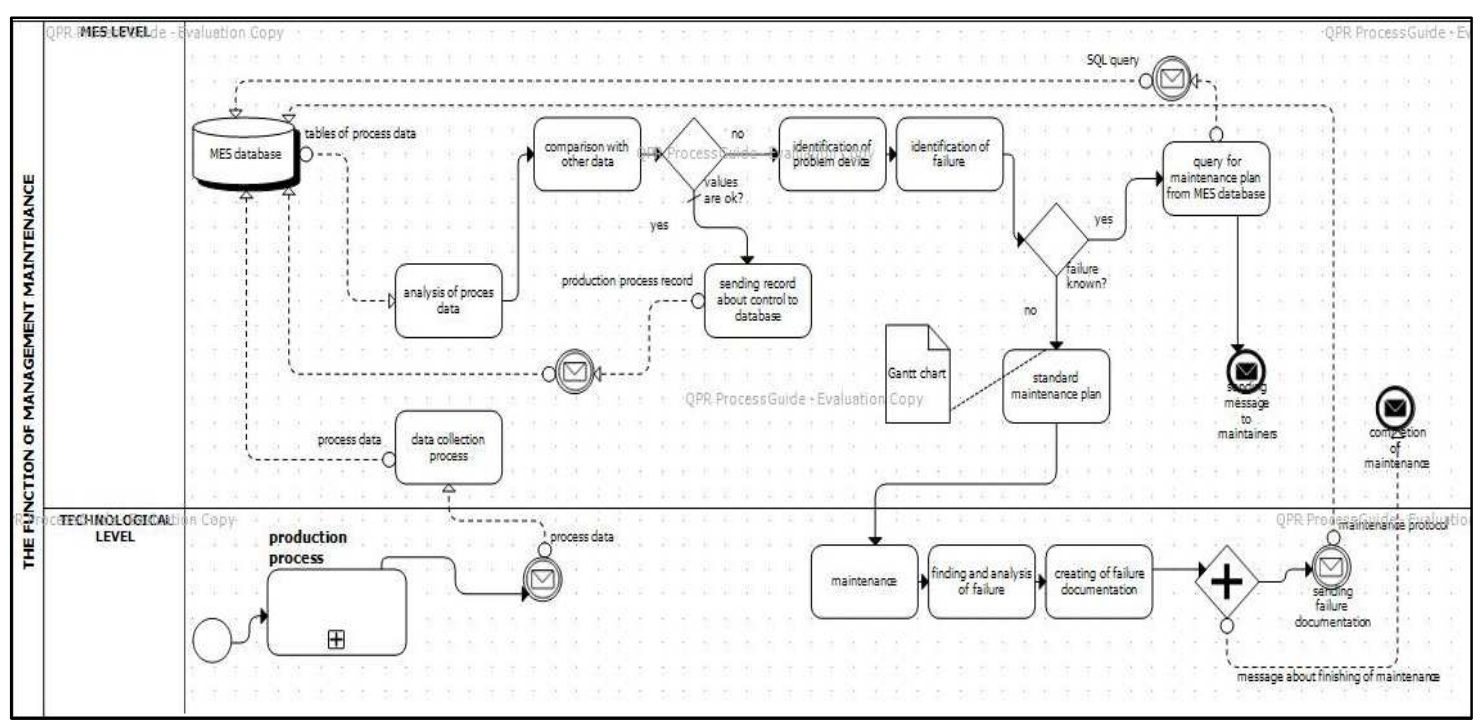

Figure $3-B P M N$ model of the function of management maintenance 


\subsection{Comparison of BPMN with Activity Diagram (UML)}

In the next section, (Table 1) we will select some of the key criteria for modelling MES. Next, we assign values from 1 to 5 to them, with 5 representation a maximum, based on a subjective feeling from modelling. We will also compare the standard BPMN (process map) and UML technology (Activity Diagram). The values were assigned based on our personal experience with this experiment. We respect these criteria:

- System dynamics,

- Technological complexity,

- Function decomposition,

- Model clarity,

- Model exactness,

- Business views.

The dynamics of the system is an important criterion for modelling MES. The BPMN standard provides a wider range of events and streams than Activity Diagram. It is understandable that the dynamics of systems is better with BPMN rather than UML. The technological complexity is the weakness of both models, but because of the same reason as in the case of the system dynamics, BPMN is a little more favourable. Clarity and Exactness of the models are again an advantage of the BPMN standard. Activity Diagram is a very close alternative to standard flowcharts, whose readability is always clearer to programmers, rather than average users and managers.

BPMN is very strong in business views. This is understandable as it was created just for business process modelling. That is why, BPMN is better than the Activity Diagram in the UML standard.

Table 1 -Criteria for modelling of MES in two approaches

\begin{tabular}{l|l|l}
\hline Criterion & BPMN (Process map) & UML (Activity Diagram) \\
\hline System dynamics & 4 & 2 \\
\hline Technological complexity & 2 & 1 \\
\hline Function decomposition & 4 & 4 \\
\hline Model clarity & 5 & 3 \\
\hline Model exactness & 4 & 3 \\
\hline Business views & 5 & 3 \\
\hline Sum of points & $\mathbf{2 4}$ & $\mathbf{1 6}$ \\
\hline
\end{tabular}




\section{CONCLUSION}

The issue of the process of modelling information systems is constantly evolving. The BPMN standard offers a number of structural elements, which may be missing in other technologies. On the other hand, it is clear that, BPMN is also insufficient for modelling such complex systems. In this article, the application of the BPMN standard for modelling the MES level for the flexible production line was described. BPMN was compared with Activity Diagram (the analysis and application of Activity Diagram is not included in this article). Based on the scoring both approaches, the BPMN standard seems to be better than UML Activity Diagram. However, this does not mean that it is fully sufficient.

Process modelling enables us to see MES system as a collection of separate processes (which represent the MES functions), and so it is possible to model these processes separately under one large model. On the other hand, the big disadvantage of this approach is the fact, that it is not possible to capture complex technological background of the system. The result of this experiment is the fact that it is still necessary to find new ways or technologies to design these information systems. A combination of existing technologies could be one of the options for future research.

\section{ACKNOWLEDGMENTS}

This publication is supported by the Scientific Grant Agency of the Ministry of Education, Science, Research and Sport of the Slovak Republic, project KEGA 021TUKE-4/2012: CyberLabTrainSystem - Demonstrator and Trainer of Information-Control Systems.

\section{REFERENCES}

Bastos, M., Ruiz, A., 2002. Extending UML Activity Diagram for Workflow Modeling in Production Systems, in Proceedings of the $35^{\text {th }}$ Hawaii International Conference on System Sciences, Hawai, 7-10 January, pp. 3786-2795.

Bordbar, B., Giacomini, L., Holding, D. J., 2000. Design of Distributed Manufacturing Systems using UML and Petri Nets, in Proceedings of Algorithm and Architectures for Real-Time Control, Palma de Mallorca, Spain, pp. 105110 .

Domínguez, G., Mariano, M., Medina, I., 2012. A comparison of BPMN 2.0 with other notations for manufacturing processes, in Proceedings AIP Conference, New South Wales, Australia, pp. 593-600.

Hošák, R., 2012. Contribution to the design of information and control systems of middle level management using the process model. Licentiate of doctor thesis: Technical University in Košice. Košice. [In Slovak]. 
Jadlovský J., Laciňák S., Chovaňák, J., Ilkovič J., 2010. Design of distributed control system of flexible production line, in Proceedings of the Cybernetic and Informatics, Vyšná Boca, Slovak Republic, 10-13 February, pp.1-6. [In Slovak].

MESA, 2012. Manufacturing Enterprise Solutions Association, Available at: <http://www.mesa.org/en/index.asp> [Accessed 15 April, 2013].

Michalik, P., 2012. Using of process map in designing of MES (Manufacturing Execution System) level of information and control system. Licentiate of engineering thesis: Technical University in Košice. Košice. [In Slovak].

Ricken M., Vogel-Heuser, B., 2010. Modeling of Manufacturing Execution Systems: An interdisciplinary challenge, in Proceedings of Emerging Technologies and Factory Automation (ETFA), 2010 IEEE Conference, Bilbao, Spain, 13-16 September, pp.1-8.

Zolotová, I., Hošák, R., Liguš J., Kubičko, P., 2011. Experiences with teaching of process modelling as a starting point in design of information systems, in Proceedings of the $22^{\text {nd }}$ EAEEIE Annual Conference, Maribor, Slovenia, 13-15 June, pp. 156-160.

Zolotová, I., Kubičko P., Landryová, L., Hošák, R., 2012a. A design of a reference model of an innovation process and its implementation in business using an innovation zone, in Proceedings of the Production Management Systems, Stavanger, Norway, 26-28 September, pp. 1-9.

Zolotová, I., Laciňák L., Mihal', R., 2012b. Data acquisition and supervisory control - communication layer and life cycle of application, in Proceedings of the Cybernetics and Informatics, Skalka pri Kremnici, Slovak Republic, $31^{\text {st }}$ January $-4^{\text {th }}$ February, pp. 1-6.

Zor, S., Görlach, K., Leymann, F., 2010. Using BPMN for Modeling Manufacturing Processes, in Proceedings of $43^{\text {rd }}$ CIRP Conference on Manufacturing Systems, Vienna, Austria, 26-28 May, pp. 1-8.

\section{ABOUT THE AUTHORS}

Ing. Peter Michalik, Technical University of Košice, Faculty of Electrical Engineering and Informatics, Department of Cybernetics and Artificial Intelligence, email: peter.michalik.2@tuke.sk.

Ing. Ján Štofa, Technical University of Košice, Faculty of Electrical Engineering and Informatics, Department of Cybernetics and Artificial Intelligence, email: jan.stofa@tuke.sk.

Prof. Ing. Iveta Zolotová, CSc., Technical University of Košice, Faculty of Electrical Engineering and Informatics, Department of Cybernetics and Artificial Intelligence, email: iveta.zolotova@tuke.sk. 